\title{
Sexualidade e Política na Cultura Contemporânea: o Reconhecimento Social e Jurídico do Casal Homossexual
}

MÁRCIA ARÁN ${ }^{1}$

MARILENA V. CORREA ${ }^{2}$

Este trabalho tem como objetivo analisar os principais dispositivos de discurso que estabelecem fronteiras e hierarquias entre práticas sexuais. Pretende-se analisar em que medida a utilização de alguns conceitos da Psicanálise, da Antropologia e do Direito são evocados para definir fronteiras entre sexualidades normais e desviantes. Para isto, serão destacadas: a construção, por aqueles discursos, do dispositivo "diferença sexual" (de hierarquia entre os sexos e de exclusão da homossexualidade) e a noção de "ordem procriativa" (atualizadora de um modelo biológico de filiação). A partir dessas premissas, nota-se que a tríade heterossexualidade-casamento-filiação permanece como a única referência possível para pensar a cultura ou a sociedade, sendo que a visibilidade ou o reconhecimento civil do laço afetivo e sexual homossexual se transforma numa ameaça de apagamento de fronteiras ou de transgressões de limites.

Palavras-chave: Sexualidade; parentesco; homossexualidade; filiação. 


\section{Introdução}

Nas últimas décadas, mudanças nas representações, práticas e identidades sexuais vêm sendo observadas. Os principais fenômenos constitutivos dessas mudanças são: a crise na família nuclear (monogâmica e heterossexual), a entrada da mulher no mercado de trabalho, a separação da sexualidade da reprodução e uma política de visibilidade da homossexualidade. Nesse contexto, o debate em torno do reconhecimento social e jurídico do casal homossexual tem sido um dos principais pontos de embate ou mesmo de subversão da cultura da scientia sexualis (FOUCAULT, 1993, p. 58), e promove deslocamentos significativos nos dispositivos de parentesco, filiação e de definição da diferença entre os sexos (ARÁN, 2003a e 2003b).

A epidemia da AIDS foi um dos fatores políticos que mais contribuíram para a emergência desse tema na esfera pública. Inicialmente, um dos principais conflitos relacionados à questão da associação entre AIDS e homossexualidade dizia respeito à necessidade de desconstruir a representação da doença como sendo uma "peste gay". Aquela associação, por um lado, reanimou uma velha onda de preconceitos contra homossexuais, e, por outro, demonstrou total despreparo por parte dos órgãos de saúde governamentais para lidar com questões relacionadas à sexualidade. As campanhas preventivas oficiais demoraram a tratar o tema da homossexualidade de forma positiva. Somente após a mobilização da sociedade civil, principalmente através da rede de solidariedade organizada pelos movimentos sociais, é que foram elaboradas políticas de prevenção mais eficazes contra a contaminação pelo HIV (BORRILLO; LASCOUMES, 2002).

Antes do surgimento da AIDS, ainda no início dos anos 80, a homossexualidade era associada, por grande parte desses movimentos, a uma forma de socialização "libertária", ou seja, a uma alternativa à sexualidade moldada pela sociedade patriarcal e heterossexual. As campanhas de prevenção ou as redes de solidariedade privilegiavam o modo de vida celibatário e a diversidade de parceiros sexuais. Foi somente a partir dos anos 90 - quando assistimos a uma inegável injustiça para com aqueles que, ao perderem seus companheiros, não tiveram acesso aos bens adquiridos com esforço mútuo, foram expulsos de suas moradias e excluídos da participação na herança - que o debate em torno do direito patrimonial colocou em evidência a questão da conjugalidade (ADAM, 1999).

Nesse contexto, ocorria intenso movimento jurídico-institucional de 
defesa dos direitos humanos, com o intuito de proteger os indivíduos da discriminação por motivos de raça, sexo, pertencimento religioso, ou mesmo orientação sexual, na América do Norte (Canadá e Estados Unidos) e em países europeus, com destaque para o histórico maio de 68 francês. A despenalização de homossexualidade - com a saída das práticas sexuais homoeróticas dos códigos penais em diversos países - e sua desmedicalização - com a retirada da categoria homossexualidade da Classificação Internacional das Doenças (CID) - foram conquistas importantes e significaram, sobretudo, uma tolerância, por parte da sociedade, em relação à liberdade do amor homossexual, desde que vivido e exercido exclusivamente no âmbito privado. Leia-se: desde que excluídos da proteção e do reconhecimento pelos códigos de direito civil. É como se a sociedade tolerasse essa prática afetivo-sexual, contanto que esta não colocasse em questão os pilares da ordem social vigente, e permanecesse à sombra do que se pretende a norma: a família nuclear e a heterossexualidade. Assim sendo, é no direito civil, ou seja, no âmbito do reconhecimento público da existência de um laço afetivo-sexual entre homossexuais, que se coloca todo o problema: um problema que diz respeito à visibilidade.

Pierre Bourdieu, no texto "Algumas considerações sobre o movimento de gays e lésbicas", afirma que "o movimento de revolta contra uma forma particular de violência simbólica, além de fazer com que existam novos objetos de análise, coloca profundamente em questão a ordem simbólica em vigor" (BOURDIEU, 1998, p. 129). O autor se refere a uma forma específica de opressão, da qual os homossexuais seriam vítimas, que se faz "pela negação da existência pública visível". Neste sentido, a manutenção da invisibilidade se daria, por um lado, pelo não-reconhecimento por parte do direito e, por outro, por uma espécie de estigma social que se manifesta justamente quando esse movimento aparece, ou seja, quando faz política. Da mesma forma, Fassin sugere pensar que o que foi concedido aos homossexuais foi uma espécie de liberdade negativa, tolerada, desde que invisível, "como se quando se falasse de homossexualidade, fosse necessário somente regular situações de fato, e não produzir sentido" (FASSIN, 1998, p. 45). É por esse motivo que o debate em torno do reconhecimento jurídico do casal homossexual provoca imediatamente uma reação conservadora, já que rompe de forma radical com a manutenção da invisibilidade.

No Brasil, desde 1995, existe um projeto de lei tramitando no Congresso Nacional, de autoria da então deputada federal Marta Suplicy (PT), que disciplina 
a "parceria civil registrada entre pessoas do mesmo sexo" ${ }^{\text {. Embora o projeto }}$ se encontre parado na Câmara dos Deputados, serviu como referência para a reflexão sobre o tema (UZIEL, 2002; RIOS, 2001). Atualmente, o Poder Judiciário tem sido solicitado para regulamentar questões que envolvam sobretudo a esfera patrimonial. Em geral, para as solicitações de partilhas de bens adquiridos em comum, quando se atribui algum direito às partes envolvidas, é pela alegação da constituição de uma "sociedade de fato". Somente em tribunais do Rio Grande do Sul tem-se observado a alegação de "união estável", conferindo-se à união homossexual o estatuto de família. Além disso, nesse estado tem sido autorizado o registro de documentos que confirmem a união e comunhão afetiva entre pessoas do mesmo sexo nos Cartórios de Registro de Notas ${ }^{4}$.

Porém, mesmo considerando a importância política do debate sobre a legitimação do casamento entre homossexuais, é importante realizarmos algumas ressalvas. A primeira delas diz respeito à necessidade de diferenciar o que se compreende hoje por "casamento gay" de parentesco homossexual. Segundo Butler (2003, p. 221), deve-se levar em conta que existem relações de parentesco que não se encaixam na norma da família nuclear reprodutiva, e que configuram redes de relações biológicas e não-biológicas que não necessariamente podem e devem ser formalizadas pelas regras jurídicas atuais. A autora afirma que parentesco é um dispositivo que não reflete uma estrutura anterior e transcendente, mas só pode ser compreendido como uma prática realizada. Sendo assim, não é uma esfera que possa se distinguir das redes de comunidade e de amizade (regulamentadas ou não pelo Estado) nas quais se insere, para se transformar num conceito ou numa categoria de análise (ultrapassada). Parafraseando Foucault, poderíamos dizer que, tal como a sexualidade, o parentesco não é uma invariante, mas sim um fenômeno histórico e contingente.

A outra ressalva, também destacada por Butler, se refere aos limites do campo da legitimidade ou, por que não dizer, da política da representabilidade. Desejar ser legitimado pelo Estado é também ter a Lei como referência, lugar de reconhecimento das práticas sexuais. Porém, como diz a autora, "compreendemos mal o campo sexual se considerarmos que o legítimo e o ilegítimo esgotam todas as suas possibilidades imanentes" (BUTLER, 2003, p. 226). Por um lado, podemos questionar a hierarquia entre as sexualidades na qual se têm baseado os mais diversos dispositivos de lei, que pretendem configurar o casal homossexual como sendo "periférico" em relação à norma heterossexual dominante. Deste ponto de vista, são evidentes a injustiça e a 
discriminação no que se refere principalmente ao acesso aos direitos civis. Por outro lado, é importante não querermos incluir na esfera da norma e da lei todos os campos das práticas sexuais que podem querer permanecer inteligíveis e não-reconhecíveis.

No entanto, é justamente na esfera da legitimidade - ou seja, na interrelação do Estado com o Poder Judiciário, os movimentos sociais, os indivíduos envolvidos e os especialistas das mais diversas áreas do saber convocados a opinar sobre a questão - que se delineia uma das formas de biopoder na atualidade (FASSIN; MEMMI, 2004). Do encontro entre uma "anatomopolítica" que pretende disciplinar indivíduos e uma "biopolítica" concebida para administrar populações (FOUCAULT, 1993, p. 2002), novas e velhas estratégias discursivas são rearticuladas, na tentativa de manutenção de um saber-poder sobre as sexualidades, as quais acabam por estabelecer fronteiras e hierarquias entre práticas sexuais. Nesses discursos, alguns conceitos da Teoria Psicanalítica e da Antropologia são evocados para definir fronteiras entre sexualidades normais e desviantes (BORRILLO; FASSIN; IACUB, 2001). Neles, ainda, duas premissas se destacam: 1) a construção do dispositivo "diferença sexual", que traz consigo ao mesmo tempo a concepção de uma hierarquia entre os sexos (BOURDIEU, 1998) e a exclusão da homossexualidade (BUTLER, 2003); 2) uma certa noção de "ordem procriativa", que reatualiza um modelo dito "biológico", no qual a filiação está necessariamente vinculada à norma heterossexual.

A partir dessas duas premissas, nota-se que a tríade heterossexualidade / casamento / filiação permanece como a única referência possível para pensar a cultura ou a sociedade, sendo que a visibilidade, ou o reconhecimento civil do laço afetivo e sexual homossexual, se transforma numa ameaça de apagamento de fronteiras e de transgressões de limites.

\section{Sobre o Dispositivo "Diferença Sexual"}

Se tomarmos como referência o debate realizado na França por ocasião da aprovação do Pacto Civil de Solidariedade (Pacte Civil de Solidarité, PACS ${ }^{5}$ ), em 1999, fica claro que são justamente os efeitos da conquista da visibilidade da conjugalidade homossexual, institucionalizada ou não, que se transformam em ameaça e causam uma reação, quase fóbica, de tentativa de preservação de uma suposta ordem simbólica. Por incrível que pareça, não foram os 
argumentos biológicos, ou os psicológicos, mesmo sendo os mais comuns, que serviram de base para uma argumentação político-científica contra o PACS, e sim aqueles que falavam da necessidade de uma "preservação simbólica" da sociedade e da cultura.

Tal argumentação parte da análise de que as sociedades democráticas contemporâneas estariam de tal forma fragilizadas, que dar o estatuto de igualdade a casais homo e heterossexuais nos levaria ao perigo de uma suposta "dessimbolização" provocada por uma política de "indiferenciação", ou seja, pelo "apagamento da inscrição da diferença sexual no simbólico" - que, para Théry $(1997,1999)$, corresponde ao plano do Direito. Segundo a autora, uma das principias mentoras dessa teoria, "nenhuma sociedade pode deixar de distinguir os homens das mulheres, as crianças dos adultos, e certamente o sexual do não-sexual" (THÉRY, 1997, p. 173). Assim, "a razão pela qual o casal homossexual não teria acesso ao casamento é que esta é a instituição que inscreve a diferença de sexos na ordem simbólica, ligando casamento e filiação" (idem). É para preservar "o simbólico", assegurado mais do que nunca pelas normas jurídicas, que, independentemente de situações de fato, a tríade heterossexualidade-casamento-filiação deve permanecer como a única referência visível, no tocante às relações entre os sexos.

Chama atenção nesse tipo de discurso a arbitrariedade do argumento que aproxima uma interpretação antropológica de uma intenção quase que teológica, já que "o simbólico", como uma categoria abstrata, paira sobre uma sociedade em transformação. Além disso, as noções de diferença sexual, casamento ou mesmo filiação são quase que naturalizadas, não levam em conta que o entrelaçamento dessas categorias, tendo como eixo central o direito, é uma experiência da modernidade. Por fim, é veiculada a idéia de que é necessário preservar esse tipo de instituição para que se preserve a cultura, como se só fosse possível pensar em formas de subjetivação tendo como referência um modelo vertical transcendente - a lei, a família e o estado desconsiderando as possibilidades horizontais de outras formas de simbolização (ARÁN, 2001).

Uma das referências que sustentam essa argumentação é uma certa interpretação da teoria psicanalítica que associa cultura à heterossexualidade. O complexo de Édipo e o complexo de castração são interpretados a partir do seu viés mais normativo, fazendo tanto do "primado genital" como do simbólico um telos em relação ao qual a homossexualidade só pode ser pensada como 
narcisismo ou perversão (COSTA, 1995). É interessante observar que, quando se trata de descrever o indivíduo homossexual, na maioria das vezes o argumento psicanalítico não se apresenta como conservador ou discriminatório, já que necessariamente a psicanálise deve tolerar todas as formas de manifestação das singularidades. O problema aparece quando as mudanças sociais e políticas, como no caso do reconhecimento do casamento homossexual, começam a fazer perecer os pilares dos sistemas teóricos que não mais se sustentariam a partir do estremecimento do dispositivo "diferença sexual", suposto fundador da cultura, e da própria teoria.

Em relação a isto, duas considerações se fazem necessárias. A primeira: não são poucos os trabalhos que demonstraram como o modelo tradicional de se pensar a diferença entre os sexos na psicanálise se baseia no modelo da primazia da heterossexualidade e da dominação masculina ${ }^{6}$. Não precisamos de muitos argumentos para demonstrar como o desenvolvimento da idéia do complexo de Édipo-castração na obra freudiana (ARÁN, 2003a) e a releitura lacaniana da lógica fálica (ARÁN, 2003b) se fundamentam, constituem e apresentam como uma versão do desejo masculino heterossexual. Herdeira do modelo de diferença sexual construído nos séculos XVIII e XIX, a lógica que pressupõe a diferença, para esses autores, gira em torno da hierarquia e da exclusão. No que se refere a Freud, a única possibilidade de destino para a sexualidade feminina é a inveja do pênis, tendo na sua versão positiva a maternidade e na sua versão negativa a renúncia e a virilização. Para Lacan, nas fórmulas de sexuação, o lado feminino acaba sendo um limite interno do masculino, em que a mulher aparece como "não toda" inscrita na função fálica. É neste sentido que a castração pode ser considerada, como sugere Stein (1977) a própria "negação da feminilidade".

A segunda consideração diz respeito ao simbólico. Nota-se que o conceito, oriundo da psicanálise e da antropologia, opera como uma matriz cultural que pressupõe uma coerência e uma continuidade entre gênero, sexo, desejo e práticas sexuais (BUTLER, 2003, p. 38). A partir de um sistema de oposições, constitui-se uma gramática dos sexos, na qual a artificialidade das relações binárias da sexualidade suprime qualquer manifestação de multiplicidade subversiva. A restrição que pesa sobre o sexo atende aos objetivos reprodutivos de um sistema de heterossexualidade compulsória (BUTLER, 2003, p. 216). Cabe salientar que, quando se permite alguma variação nessa continuidade substantiva dos sexos, a mesma matriz de pensamento continua 
operando, procurando identificar novas coerências (como por exemplo mulher masculina / homem feminino, mulher homossexual / homem homossexual).

Assim, as oposições feminino / masculino, sexo / gênero, heterossexualidade / homossexualidade, natureza / cultura compõem uma matriz binária do pensamento sobre o corpo e a sexualidade, no qual qualquer manifestação subjetiva que subverta essa lógica ou passa a ser considerada impensável, ou é vista como uma ameaça para a sobrevivência da própria sociabilidade.

No entanto, já existem vários trabalhos no campo da filosofia, da psicanálise e também da antropologia, que consideram que esse pensamento mecânico e dualista é historicamente contingente e que muito contribuiu para estabelecer hierarquias entre as subjetividades (RIOS, 1998; LOYOLA, 1998). Isto não significa dizer que o questionamento do modelo da diferença sexual pretenda acabar com toda e qualquer forma de diferenciação. Pelo contrário, pressupor a singularidade e a plasticidade das sexualidades é uma forma de repensar justamente o conceito de alteridade (ARÁN, 2003b; AGAMBEM, 1990; PEIXOTO JÚNIOR, 2003).

\section{Sobre a Noção de "Ordem Procriativa"}

O debate em torno da filiação homoparental suscita inúmeras polêmicas. Muitas vezes chega a ser considerada uma verdadeira ameaça para a cultura e para a sobrevivência da espécie. É interessante observar que essa lógica é implícita, porque nunca se chega a dizer ou mesmo comprovar por que a homossexualidade dos pais constituiria uma ameaça para a saúde ou para o direito da criança.

Segundo Marcela Iacub, por "ordem procriativa entende-se um conjunto de normas jurídicas que organizam as formas de inscrição genealógica e de reprodução biológica das pessoas", a qual se estrutura com base em três grandes pilares: a liberdade de procriar por via natural; a assimilação da categoria de genitor a categoria de pai; a equivalência entre capacidades reprodutivas e capacidades parentais (IACUB, 2001, p. 197).

Desta forma, a liberdade procriativa não encontra limites quando se trata de casais heterossexuais em idade fértil, já que estes reproduzem exatamente o modelo biológico. Nesse caso, não se cogita um eventual prejuízo 
para a criança que vai nascer, nem a aptidão dos pais, já que supostamente a competência procriativa garante a competência parental. Porém, quando para procriar é necessário recorrer a técnicas artificiais, a liberdade procriativa é colocada sob suspeita, passando a estar submetida ao debate e à regulação no plano das normas (médicas, bioéticas, jurídicas) e mesmo da Lei. Desse modo, o acesso às técnicas alternativas para produzir ou criar uma criança não é franqueado a todos que querem transmitir a vida. A desigualdade das performances corporais, quer seja no nível dos indivíduos quer dos casais, são hierarquizadas e normatizadas de acordo com o modelo biológico (BORRILLO, 2004). E, efetivamente, na maior parte das vezes, o direito vem organizando o acesso às técnicas de reprodução medicamente assistida, de modo a fazer crer que é o ato sexual e não um artifício tecnológico que dá origem à criança nascida por essas vias (IACUB, 2001).

Assim, quando a norma jurídica define que somente casais heterossexuais têm direito a ter acesso às tecnologias de reprodução assistida, reafirma-se um princípio de direito fundamentado na potencialidade biológica de procriação. Isso torna o ato sexual heterossexual a norma procriativa mesmo quando ele não ocorre. A fecundação in-vitro retirando óvulos e espermatozóides dos corpos de homens e mulheres autonomiza completamente a reprodução da sexualidade. E mais que isso; quando se tem, na reprodução assistida, a utilização de terceiros - doadores de sêmen, de óvulos, de embriões - produz-se, de um ponto de vista biológico (e social), a desvinculação total entre as pessoas envolvidas no projeto procriativo e os fornecedores de material biológico reprodutivo (CORRÊA, 2001).

Curioso jogo de simulações que estabelece $a$ priori que a competência parental se baseia na potencialidade biológica. Não se indagam as condições materiais e emocionais para receber uma criança. Como forma de sexualidade suposta e ritualizada, a heterossexualidade é apresentada não somente como natural, mas também como culturalmente necessária ${ }^{7}$.

Para concluir, o que nos interessa deixar como possibilidade de reflexão é que, independentemente do fato de o casamento entre homossexuais se institucionalizar ou não, a visibilidade e o aprofundamento do debate podem ser uma oportunidade para se começar a pensar em novas formas de laços sociais. Onde a pluralidade das sexualidades e os modos de vida não estejam necessariamente vinculados a uma lei estabelecida a priori. Como diz Foucault:

"A homossexualidade é uma ocasião histórica para reabrir as virtualidades 
relacionais e afetivas, não pelas qualidades intrínsecas ao homossexual, mas porque sua posição 'de viés', de algum modo, as linhas diagonais que ele pode traçar no tecido social, permitem aparecer essas virtualidades" (FOUCAULT, 1994, p. 196).

\section{Referências}

ADAM, P. Bonheur dans le ghetto ou bonheur domestique? Enquête sur l'évolution des expériences homosexuelles. Actes de la recherche em sciences sociales, Paris, n. 128, p. 56-57, Juin 1999.

AGAMBEN, G. La Communauté qui vient. Théorie de la singularité quelconque. Paris: Seuil, 1990.

ARÁN, M. Os destinos da diferença sexual na cultura contemporânea. Revista Estudos Feministas, Florianópolis, v. 11, n. 2, p. 399-422, 2003 c.

. Lacan e o feminino: algumas considerações críticas. Natureza

Humana: Revista Internacional de Filosofia e Práticas Psicoterápicas, São Paulo, v. 5, n. 2, p. 293-328, 2003b.

. A sexualidade feminina e a crise da idéia de identidade. Alter: Jornal de Estudos Psicanalíticos, Brasília, v.22, n. 1, p. 107-125, 2003 a.

O avesso do avesso: feminilidade e novas formas de subjetivação. 2001. Tese (Doutorado em Saúde Coletiva) - Instituto de Medicina Social, UERJ, Rio de Janeiro, 2001.

BIRMAN, J. Cartografias do feminino. Rio de Janeiro: Editora 34, 1999.

BOURDIEU, P. Quelques questions sur le mouvement gay et lesbien. In: . La domination masculine. Paris: Seuil, 1998. p. 129-134.

BUTLER, J. Problemas de gênero: feminismo e subversão da identidade. Rio de Janeiro: Civilização Brasileira, 2003.

O parentesco é sempre tido como heterossexual? Cadernos Pagu, n. 21, p. 219-260, 2003.

BORRILLO, D. La surveillance juridique des pratiques sexuelles legitimes. In: FASSIN, D.; MEMMI D. Le gouvernement des corps. Paris: EEHESC, 2004. 
BORRILLO, D.; LASCOUMES, P. Amours égales? Le Pacs, les homosexuels et la gauche. Paris: La Découverte, 2002.

BORRILlO, D.; FASSIN, E.; IACUB, M. Au-delà du PaCS. L'expertise familiale à l'épreuve de l'homosexualité. Paris: Puf, 2001.

COSTA, J. F. A face e o verso: estudos sobre o homoerotismo II. São Pulo: Escuta, 1995.

CORREAA, M. Novas tecnologias reprodutivas: limites da biologia ou biologia sem limites? Rio de Janeiro: EdUERJ, 2001.

FASSIN, E. L'illusion anthropologique: homosexualité et filiation". Famille, nouvelles unions, bonheur privé et cohésion sociale. Paris, v. 12,p. 42-56, 1998.

FABRE, C. L'homosexualité, du code pénal au code civil. Le Monde, Paris, $1^{\circ}$ abril 1999.

FASSIN, D.; MEMMI, D.; Le gouvernement des corps. Paris: EEHESC, 2004.

FOUCAULT, M. História da Sexualidade. Rio de Janeiro: Graal, 1993. v.1

. De l'amitié comme mode de vie. In: . Dits et écrits. Paris:

Gallimard, 1994.

IACUB, M. Homoparentalité et ordre procréatif. In: BORRILLO, D.; FASSIN, E.; IACUB, M. Au-delà du PaCS. L'expertise familiale à l'épreuve de l'homosexualité. Paris: Puf, 2001.p. 193-208.

LAQUEUR, T. Making sex, body and gender from the Greeks to Freud. Cambridge: Harvard University Press, 1994.

LOYOLA, M. A. (Org.). A sexualidade nas ciências humanas. Rio de Janeiro: EdUERJ, 1998.

MOÁS, L. Filiação homossexual: os critérios de determinação do parentesco entre pais de mesmo sexo e seus filhos. 16 p, 2003. Mimeografado.

NERI, R. Modernidade: o encontro histórico da psicanálise com a histeria. Clarice Lispector e Marguerite Duras: o feminino como cultura da feminilidade. 1999. Tese (Doutorado em Teoria Psicanalítica) - Instituto de Psicologia, UFRJ, Rio de Janeiro, 1999. 
NUNES, S. A. O corpo do diabo entre a cruz e a calderinha: um estudo sobre a mulher, o masoquismo e a feminilidade em Freud. Rio de Janeiro: Civilização Brasileira, 2000.

PEIXOTO JUNIOR, C. A. Individuação impessoal, singularidade qualquer e a comunidade que vem. Revista Polêmica, n. 10, 2003. Disponível em < http:// www2.uerj.br/ labore/texto oficina bioetica p10.htm $>$ Acesso em agosto 2004. RIOS, A. O desejo de uma sexualidade inumerável. In: LOYOLA, M. A. (Org.). A sexualidade nas ciências humanas. Rio de Janeiro: EdUERJ, 1998. p. 159173.

RIOS RAUPP, R. A homossexualidade no Direito. Porto Alegre: Livraria do Advogado, 2001.

THÉRY, I. Le contrat d'union sociale en question. Esprit, Paris, p. 159-187, Oct. 1997.

Couple, filation et parenté aujourd'hui. Le droit face aux mutations de la famille et de la vie privée. Paris: Éditions Odile Jacob, 1999.

STEIN, C. La mort d' EEdipe. Paris: Méditations, 1977.

UZIEL, A. P. Família e homossexualidade: velhas questões, novos problemas. 2002. Tese (Doutorado em Ciências Sociais) - Instituto de Filosofia e Ciências Humanas, UNICAMP, 2002.

\section{NOTAS}

${ }^{1}$ Psicanalista; professora visitante do Departamento de Políticas e Instituições de Saúde do IMS / UERJ; psicóloga do Hospital Universitário Clementino Fraga Filho / UFRJ. E-mail: marciaaran@ig.com.br

${ }_{2}^{2}$ Médica psiquiatra e sanitarista; doutora em Saúde Coletiva; professora adjunta do Departamento de Políticas e Instituições de Saúde do IMS / UERJ. E-mail: mcorrea@ism.com.br

\footnotetext{
${ }^{3}$ Projeto de Lei $n^{\circ} 1.151$, de 1995.

${ }^{4}$ Artigo 215 da CNNR-CGJ.

5 "Pacto civil de solidariedade que pode ser concluído por duas pessoas físicas, independentemente do seu sexo para organizar sua vida comum" (BORRILLO, 2001, p. 892-894).

${ }^{6}$ Ver Arán (2001), Birman (1999), Neri (1999) e Nunes (2000).
} 
${ }^{7}$ Para um aprofundamento do debate jurídico sobre o direito à filiação homossexual no Brasil, ver Moás (2003).

\section{ABSTRACT}

\section{Sexuality and Politics in Contemporary Culture: social and legal recognition for gay couples}

This study aims to analyze the main discursive devices that establish borders and hierarchies among sexual practices. The objective is to analyze to what extent the utilization of certain concepts from psychoanalysis, anthropology, and law are invoked to define borders between normal and deviant sexualities. The following points are highlighted: the construction, by these discourses, of the "sexual difference" device (hierarchy between the sexes and exclusion of homosexuality) and the notion of "procreative order" (updating a biological model of filiation). Based on these premises, one notes that the heterosexuality-marriage-filiation triad remains as the only possible reference to conceive of culture or society, while the visibility or civil recognition of homosexual affective and sexual ties threatens to erase borders or transgress limits.

Key words: Sexuality; kinship; homosexuality; filiation.

Recebido em: 28/09/2004.

Aprovado em: 18/10/2004. 